\title{
PSICOLOGIA E BIOLOGIA: ALGUMAS INTERSEÇÕES ${ }^{1}$
}

\section{Flávia Sollero-de-Campos Monah Winograd}

Resumo:São selecionados alguns conceitos relevantes para o entendimento da importância da biologia contemporânea para a psicologia com o objetivo de analisar as possibilidades de aproximação entre os dois campos. Para isso, primeiramente são apresentadas algumas questões teóricas, metodológicas e epistemológicas envolvidas na aproximação entre psicologia e biologia, que com frequência são negligenciadas. A seguir, faz-se um breve histórico dos desenvolvimentos da biologia e de algumas de suas apropriações de outros campos teóricos no decorrer do século XX. Após breve apresentação das aproximações teóricas já realizadas entre os dois campos de saber em questão, sugere-se que esse seria um primeiro passo para uma interlocução informada e interessada entre ambos os campos.

Palavras-chave: Biologia. Psicologia. Interdisciplinaridade. Conexionismo.

Atualmente tem sido bastante discutidas, sob a ótica dos profissionais do campo psi, as relações entre a psicologia e diversas subáreas da biologia. Em geral, observamos inúmeras dificuldades no acompanhamento das transformações pelas quais passa a biologia. Por vezes, parece que nós, psicólogos, não nos interessamos o suficiente em conhecer mais de perto nem certos desdobramentos teóricos, nem a inesperada interseção entre diferentes campos científicos e biologia. Com isso, debates relevantes quanto às questões teóricas, metodológicas e epistemológicas envolvidas na aproximação entre psicologia e biologia, por exemplo, são negligenciados. No entanto, a consideração da relevância de tais debates, bem como o encaminhamento da discussão de maneira profícua, implica necessariamente que não vejamos a bio-

1 Trabalho realizado com o financiamento do CNPq. 
logia apenas como uma ciência que pesquise e proponha somente algum tipo de substrato material para os processos abordados pelo campo psi. Como propõe Kuhn (1962/2003), podemos pensar, mais profundamente, que tal ciência - como qualquer ciência - é constituída por uma linguagem diversa, com sua respectiva ontologia e em sua respectiva especificidade (Coutinho, 1996).

É bem verdade que a sugestão de que as teorias poderiam ser incomensuráveis (Kuhn, 1962/2003; Feyerabend, 1981/1985) dificultou muito a aproximação entre sistemas conceituais diferentes, como a biologia e a psicologia. Porém, se é certo que teorias científicas sobre temas próximos realmente podem ocupar sistemas conceituais muito diferentes, também é certo que, em geral, existem suficientes possibilidades de superposições conceituais, linguísticas e até em termos de evidências que podem permitir uma eventual aproximação. Aliás, os escritos mais recentes de Kuhn (1977) apontam para a incomensurabilidade, não mais como um impedimento radical à possibilidade de comparação entre teorias, mas sim somente com relação às dificuldades de tradução e de comunicação entre teorias. Nesse sentido, não se consideraria a impossibilidade de inteligibilidade entre teorias, mas, simplesmente, a impossibilidade de tradução parcial ou total de um esquema conceitual em outro.

Por sua vez, Buchwald (2001) propõe a comensurabilidade de dois esquemas conceituais quando suas estruturas lexicais podem se ajustar. A primeira forma de ajuste seria a possibilidade de tradução direta de uma para a outra, o que significa que haveria um isomorfismo, mesmo que parcial, entre as teorias em questão. Assim, um esquema estaria subsumido no outro. Na segunda possibilidade de ajuste, uma estrutura poderia ser colocada diretamente sobre a outra, sem haver nenhuma perturbação nas relações já existentes nessa última. Nesse segundo caso, a partir dos dois esquemas prévios, formar-se-ia um novo esquema, porém preservando intactas todas as relações anteriores já existentes. A proposta de Buchwald é interessante, pois suaviza as afirmações de Laudan (1997), para quem dois campos discursivos são incomensuráveis se a afirmação feita em um deles é ininteligível para aqueles que utilizam o outro.

Ora, sabemos que o significado de um conceito é uma questão tanto de sua relação com outros conceitos quanto de sua relação com o mundo. Ainda que existam diferenças ontológicas, explanatórias, linguísticas ou conceituais entre abordagens ou esquemas teóricos, esses não precisariam ser considerados tão díspares a ponto de se pensar que habitariam diferentes mundos. Se assim fosse, de maneira tão radical quanto primeiramente pensado por Kuhn, não haveria possibilidade de interdisciplinaridade. Pensemos rapidamente em todo o movimento interteórico que vem se desenvolvendo desde a década de 1940, abrangendo a biologia, a teoria da informação, a linguística, a psicologia, a filosofia, a inteligência artificial, a matemática e a antropologia desse ponto de vista. Se, no início do século 
$\mathrm{XX}$, as universidades tinham se estabilizado num conjunto de disciplinas divididas em científicas e humano-sociais - o que ainda se mantém -, atualmente, esse princípio organizador bastante conveniente tem sido rompido por pesquisas que atravessam essas fronteiras ou que operam nas fronteiras entre duas disciplinas bem definidas.

Latour (1988/2000) destaca que uma parte relevante dos Estudos de Ciência consiste justamente no estudo das operações de translação continuamente realizadas entre, por exemplo, o científico e o político, o ideológico e o político, e vice-versa. Para Latour, transladar (ou traduzir) consiste em deslocar interesses, objetivos, dispositivos técnicos, seres humanos, inventando elos que ainda não existiam e que vão modificar suas relações. $O$ autor chama de tradução"a interpretação dada pelos construtores de fatos aos seus interesses e aos das pessoas que eles alistam" (p. 178). Além disso, "traduzir interesses significa... oferecer novas interpretações desses interesses e canalizar as pessoas para direções diferentes" (p. 194). O autor se dedica exatamente à análise dessas translações/traduções que implicam invenções, deslocamentos, mediações e produção de vínculos até então inexistentes. Tais procedimentos modificam os anteriores, considerados como os "originais",e criam novas interações entre disciplinas. Esse é exatamente o ponto que consideramos relevante nesse artigo.

Vejamos o caso da neurociência. A literatura neurocientífica é bastante limitada no que tange a aspectos que não lhe são específicos. Por exemplo, de que maneira os resultados de suas pesquisas se inserem no entendimento do contexto sociocultural e dos processos de estruturação da subjetividade, temas mais afins a teorias como a psicanalítica? Por outro lado, não seria aquela literatura relevante, já que não podemos simplesmente ignorar a dimensão biológica humana, como sói acontecer nas ciências humanas e sociais? Acreditamos serem as teorias biológicas, especificamente a neurociência contemporânea, interessantes na medida em que podem nos ajudar a problematizar algumas questões relativas aos diferentes graus e formas de constrangimentos tanto no que diz respeito à nossa plasticidade (inclusive a neuronal), quanto no que se refere às nossas preferências (que usualmente compreendemos apenas do ponto de vista individual). Contudo, se, por um lado, defendemos a relevância das contribuições das teorias biológicas em geral e neurocientíficas em particular, por outro lado, não consideramos que devam ser incorporadas acriticamente às teorias da subjetividade. Com efeito, trata-se de levar em conta as contribuições dos discursos biológicos como subsídios fecundos para os movimentos de pensamento próprios ao nosso campo.

Nosso objetivo é, assim, traçar um breve panorama do contexto histórico e epistemológico no qual surgiram conceitos que podem funcionar como pontos de passagem entre a biologia e a psicologia, tais como evolução, sistema, auto-organização, cognição. Não se trata aqui de investigá-los à exaustão, mas de circunscrevê-los, destacando algumas discussões que 
os envolveram e ainda envolvem. Veremos como o percurso do discurso biológico abrange um amplo leque de contribuições de teorias oriundas de várias ciências. Acreditamos que qualquer análise das contribuições da biologia e das áreas conexas para as ciências humanas deve começar pelo entendimento da complexidade teórica envolvida.

\section{Breve panorama da biologia do século XIX ao século XX:}

\section{Darwin e a teoria da evolução}

As grandes transformações conceituais pelas quais tem passado o estudo dos seres vivos originam-se de vários domínios que têm entrado em conjunção estratégica desde o século XIX. Resumidamente, podemos assinalar alguns marcos importantes: a termodinâmica (particularmente, sua segunda lei e o conceito de energia); a teoria celular de Virchöw e seus desdobramentos (tais como a citologia), que possibilitaram a pesquisa das células e de suas organelas a partir de microscópios cada vez mais precisos e de novas técnicas de manuseio e de coloração em laboratório; a distinção, no decorrer da segunda metade do século XIX, entre química orgânica e inorgânica e o posterior surgimento da bioquímica (Jacob, 1970/1983); os estudos em estatística e probabilidade que possibilitaram a pesquisa de grandes populações, não em termos deterministas estritos, e sim em termos de leis estatísticas probabilísticas, viabilizando a consideração de outro tipo de determinismo, a contingência.

Para além de todas essas contribuições, a teoria darwiniana mostrouse uma extraordinária articuladora teórica. Na medida em que propôs explicar a ligação evolucionária entre as mais diferentes espécies animais, possibilitou a formulação de analogias e comparações entre as espécies animais, inclusive os humanos. Com isso, a utilização de animais em pesquisa tornou-se justificável ao viabilizar estudos que, por razões éticas, não poderiam ser realizadas em humanos. ${ }^{2}$ Ampliada a partir da fisiologia e articulada às várias transformações citadas acima, a biologia foi se desenvolvendo como disciplina específica, isto é, como o estudo da vida em suas várias formas. Incluídos irrevogavelmente nessa agenda encontram-se as concepções de seleção natural, adaptação, sobrevivência do mais apto, desenvolvimento, organismo, função.

A partir do século $X X$, a concepção pós-darwinista de evolução vem utilizando a metáfora do "bricolage"3 (Jacob, 1970/1983) para explicar o processo evolutivo. Não mais recorre ao ponto de vista adaptacionista original que considerava que a seleção natural atua para a manutenção de um comportamento, de uma espécie, de um mecanismo, a partir de sua

2 Cabe assinalar que atualmente existe uma grande e relevante querela em termos de abusos e maus-tratos a animais em pesquisas, e sua interdição pelas mesmas razões éticas.

3 Termo utilizado por Claude Lévi-Strauss (1968) para referir-se ao processo pelo qual indivíduos e culturas utilizam os objetos ao seu redor para criar, desenvolver e apreender idéias. 
contribuição para a sobrevivência. Na perspectiva pós-darwinista, a seleção descartaria aquilo que não tem valor para a reprodução e a sobrevivência. Esses dois pontos permanecem fundamentais, porém são analisados, não mais do ponto de vista de uma lógica prescritiva, mas sim proscritiva, onde não existe um guia rígido para o processo de seleção das espécies. O que importa é que satisfaça os dois constrangimentos básicos da sobrevivência e da reprodução e, para isso, "o que não é proibido é permitido" (Varela, Thompson, \& Rosch 1991, pp. 195-200). Nesse sentido, ainda nas palavras de Varela et al. (1991), o processo evolutivo"muda da seleção ótima para a viabilidade" (p. 196). Mais importante, "a precisão e a especificidade de traços morfológicos ou fisiológicos, ou de capacidades cognitivas, são inteiramente compatíveis com sua aparente irrelevância para a sobrevivência" (p. 196).

Quanto ao conceito de evolução, autores como Gould (1992) consideram que existem quatro equívocos básicos. O primeiro é a consideração do processo evolutivo como "progresso", como um vetor que caminharia da menor para a maior perfeição. O segundo engano é entender ser a evolução determinada, ou seja, supor que certos fatores instrínsecos determinariam seu curso, deixando pouco ou nenhum lugar para a contingência. O terceiro equívoco é considerar o processo evolutivo como necessariamente gradual, ignorando os saltos que podem ser verificados ao longo da filogenia. Finalmente, o quarto engano é entender a evolução como ideologia adaptacionista, ou seja, supor que seus caminhos são regidos exclusivamente pelo grau de adaptabilidade. Com isso, Gould também está afirmando o primado da contingência: para ele, portanto, não se trata nem de acaso, nem de necessidade.

Seja como for, é certo que, em 1869, Charles Darwin situou, de uma vez por todas, o cérebro e a mente (especificamente, a consciência) no campo do natural, retirando-os do transcendental. A consciência seria, então, a resultante do desenvolvimento da modificação das espécies pela seleção natural (Schultz \& Schultz, 2005). Pouco depois em 1890, William James (Schultz \& Schultz, 2005), então psicólogo, foi o primeiro a propor uma transformação radical da psicologia — ciência recente na época — no sentido de que não mais estudasse os elementos da mente/consciência, passando a estudar as funções dos diversos comportamentos e da própria consciência na história de adaptação.

\section{Os anos 1950 e as transformações na biologia: sistema, autonomia e auto-organização}

A partir do final da Segunda Guerra Mundial, começa a reinar uma grande euforia na biologia e áreas próximas, proporcionada pela implementação da cibernética. Sendo mais precisos, não seria apenas a cibernética a responsável por toda essa transformação. Acrescenta-se a ela a teoria 
da informação de Claude Shannon (Atlan, 1986/1992) e a teoria geral de sistemas de Ludwig Von Bertalanffy (1956/1968). A biologia nos anos pósguerra modificou-se, então, radicalmente a partir da conjugação das três teorias citadas, constituindo a Biologia Molecular, projeto ao qual aderem, entusiasmados, Henri Laborit, Jacques Monod, François Jacob, dentre outros. Em 1953, Watson e Crick, apoiados nas teorias acima, determinam teoricamente a estrutura do DNA, propondo o modelo da dupla hélice e abrindo caminho para pesquisá-lo. Os trabalhos posteriores, desenvolvidos por inúmeros cientistas, explicam o DNA como base material dos genes, e a sua característica de poder replicar-se de maneira a assegurar o que Monod (1970) afirmara ser o traço inconfundível da distinção entre o orgânico e o inorgânico: a invariância reprodutiva.

A primeira transformação marcante começou a se manifestar com a publicação do livro "Cybernetics" em 1948, por Norbert Wiener, e com os primeiros desenvolvimentos da teoria dos sistemas criada por Ludwig Von Bertalanffy (1956/1968). Com isso, pode-se dar início a uma ciência da organização. É evidente que a idéia de sistema, no sentido de um conjunto organizado, não é exatamente nova. Se, desde o século XVIII já havia a concepção do ser vivo como organizado, com o surgimento da biologia no século XIX, o corpo vivo passou a ser pensado como organismo. Mas, qual teria sido então a novidade do século XX?

A concepção cibernética consistia na ampliação do estudo dos processos de comunicação e de controle no que tange à determinação das atividades das máquinas, dos seres vivos e dos processos sociais, através do conceito fundamental de feedback (retroação). Esse conceito apresentanos a possibilidade de um sistema cuja causalidade é em anel: seus efeitos exercem efeitos sobre as causas e as modificam. Posteriormente, essa concepção será denominada recursividade ou clausura operacional por autores como Atlan (1986/1992) e Maturana e Varela (1984). Esse desdobramento é crucial, pois se propõe a viabilizar a antiga proposta da concepção científica mecanicista desde Descartes e Leibniz: a idéia de uma matematização da natureza, e da extensão do conceito de mecanismo ao estudo dos seres humanos.

Segundo o Oxford Companion to the Mind (Blackburn, 1988), fisiologistas do século XIX já consideravam essenciais alguns aspectos do controle em sistemas biológicos: a organização complexa dos organismos, a relativa constância de certos parâmetros fisiológicos e a descrição do comportamento animal usando termos teleológicos (isto é, finalistas). Em 1828, Charles Bell publica Animal Mechanics (Blackburn, 1988), onde compara a estrutura óssea à engenharia e à arquitetura, e o funcionamento do coração e do sistema vascular a bombas e tubos usados na engenharia. Teria sido Bell o primeiro a comparar de maneira sistemática os organismos às máquinas, usando-as como modelo explicativo. Claude Bernard, em 1878, propôs o conceito de constância do meio interno para explicar a manu- 
tenção de constantes fisiológicas (composição do sangue, nível de glicose, temperatura corporal, por exemplo) a partir de processos reguladores que mantêm a estabilidade do organismo, mesmo havendo mudanças ambientais. Esse conceito de constância do meio interno foi desenvolvido posteriormente por Walter Cannon (Mello Filho, 1994), culminando na elaboração do célebre termo 'homeostase' para referir-se à idéia do feedback como um princípio fisiológico fundamental. Vale mencionar que Cannon propôs esta ideia - das formas de produção de estabilidade em sistemas dinâmicos - antes que Norbert Wiener, Ross Ashby e Grey Walter apresentassem o conceito de cibernética.

Como exemplo de feedback, temos a situação da manutenção da temperatura corporal nos organismos vivos. A homeotermia é uma das propriedades da homeostase, definida como a capacidade de o organismo produzir e manter constantes os seus constituintes físico-químicos, mantendo, portanto, a vida. Assim, tem-se, a partir desse conceito, a possibilidade de conceber uma causalidade interna que, até certo ponto, torna o organismo relativamente independente do meio externo. Isto é, torna-se mais próxima a possibilidade de se pensar o vivo como autonomia.

Além do feedback, outro conceito fundamental surgiu a partir da idéia de sistema. Afirma-se quase com banalidade atualmente que um todo organizado tem propriedades que não estão presentes nas suas partes;'o todo não é a soma das partes'. Entende-se que a interação das partes faz com que emerjam propriedades até então não existentes. Mais ainda, tais propriedades emergentes exercem efeitos de feedback sobre o sistema, modificando sua constituição e gerando novos efeitos. Temos aqui, novamente, o tema da autonomia de uma organização a partir dos conceitos de feedback e de emergência.

Von Bertalanffy (1956/1968) acrescentava ainda outra qualificação à noção de sistema: sua abertura. Um sistema aberto é aquele que está em contínua troca de energia e de informação com o meio externo. Assim, um organismo vivo é um sistema aberto que só se mantém vivo por ser capaz de se reorganizar continuamente. Ele mantém sua autonomia - necessariamente relativa - através da sua relação com o meio externo. Dito de outro modo, o organismo vive na dialética autonomia/dependência, continuamente se desfazendo e refazendo.

Além do feedback e da emergência, outro conceito fundamental foi cunhado no século passado: o de auto-organização. Ela pode aparecer no universo físico e é característica de todo organismo vivo. Consiste na capacidade de os sistemas estarem continuamente se autoproduzindo a partir de seus processos internos, incluindo a autorreorganização. Esse conceito é muito mais amplo e complexo que o conceito de feedback, envolvendo simultaneamente múltiplos processos, fazendo emergirem novas propriedades que irão complexificar a relação deste organismo com o meio exterior. 
Temos, então, enlaçados, os conceitos de autonomia, sistema e autoorganização. Prigogine ampliou a interação desses conceitos ao chamar a atenção para o fenômeno do caos, repensando o conceito de sistema e propondo o conceito de estruturas dissipativas. Para ele, os sistemas abertos/longe do equilíbrio (estruturas dissipativas) não necessariamente se desfazem, mas, ao contrário, podem permitir a emergência de novos sistemas. E assinala que auto-organizador seria todo sistema que, perante perturbações aleatórias, ao invés de ser destruído, reagiria com um aumento de complexidade (Prigogine \& Stengers, 1984).

Cibernética, cognitivismo e conexionismo: homens e máquinas

Dupuy (1996), em seu livro Nas origens das ciências cognitivas, faz um registro e um balanço das famosas Conferências Macy, que se realizaram entre 1943 e 1953, reunindo regularmente um grupo heterogêneo de pesquisadores que "tinha como ambição edificar uma ciência geral do funcionamento da mente" (p. 9). Pretendiam pensar a mente com ferramentas lógicas de modo que os seres vivos fossem estudados como "máquinas naturais", isto é, lógicas. E também pretendiam viabilizar a construção de máquinas lógicas que apresentassem características inteligentes. Nessas conferências, para onde acorriam os pesquisadores das mais diversas áreas - matemáticos, físicos, lógicos, fisiologistas, linguistas, psicólogos, antropólogos, economistas, sociólogos, e um único psicanalista e neurologista de formação - , foram formulados e desenvolvidos os conceitos de informação, sistema, feedback, e mais programação, automação, comunicação, simulação, para citar só alguns.

Dupuy (1996) resume de maneira inestimável o escopo das contribuições da cibernética para a nossa época:

Seu [da cibernética] projeto teórico, ideológico e técnico moldou a nossa época como nenhum outro. Ela... introduziu a conceituação e o formalismo lógico-matemáticos nas ciências do cérebro e do sistema nervoso; concebeu a organização das máquinas de processamento de informação e lançou os fundamentos da inteligência artificial; produziu a "metaciência" dos sistemas, a qual deixou sua marca no conjunto das ciências humanas e sociais, da terapia familiar à antropologia cultural; inspirou fortemente inovações conceituais na economia, na pesquisa operacional, na teoria da decisão e da escolha racional, na teoria dos jogos, na sociologia, nas ciências do político e em muitas outras disciplinas; forneceu na hora certa a várias "revoluções científicas" do século 20 -, muito diversas, pois vão da biologia molecular à releitura de Freud feita por Lacan -, as metáforas de que precisavam para assinalar sua ruptura em relação a paradigmas estabelecidos. (p.44) 
A ciência, que naquele momento se constituía, apresenta-se ainda hoje como interdisciplinar, reunindo diferentes pesquisadores em torno de um objetivo aparentemente comum: o de construir uma ciência fisicalista da mente a partir de uma nova concepção de máquina.

Todavia, para construir tal ciência - dita nova - era preciso utilizar conceitos provenientes do domínio da investigação da mente. Apresentava-se, nesse momento, uma grave questão. Conceitos como percepção, atenção, memória, linguagem, processos criativos, etc., eram áreas da psicologia desde a psicologia das faculdades wundtiana e tinham sido afastados por serem considerados não-científicos pelos comportamentalistas. O projeto de uma psicologia que incluísse tais preocupações permanecia na corrente gestaltista - aliás, muito presente no grupo inicial das conferências Macy, da qual participaram psicólogos gestaltistas notáveis como W. Köhler, K. Lewin e M. Wertheimer. Àquela época, os ciberneticistas precisavam dessas conceituações a fim de poder lidar com a questão do conhecimento: como se conhece o mundo? Como um ser vivo constitui sua capacidade de lidar com as situações percebidas e memorizadas? Somente assim seria possível construir algum artefato que tivesse alguma característica "humana".

Tanto Dupuy (1996) quanto Varela et al. (1991) consideram fundamental o papel de McCullogh (neuropsiquiatra) e Pitts (matemático) na formulação de uma"neurologia da mente".Seu artigo seminal data de 1943, com o título "A Logical Calculus of the Ideas Immanent in Nervous Activity" (McCullogh \& Pitts, citados em Dupuy, 1996). Baseados na tese de Turing, afirmavam ser a mente uma máquina lógico-matemática encarnada no organismo. $\mathrm{O}$ modelo de cérebro proposto tinha a forma de uma rede neuronal, ou seja, uma rede de conexões entre neurônios tratados como calculadoras artificiais. É interessante notar que os autores foram corrigindo e complexificando suas concepções. Assim, já em 1946, apresentaram suas primeiras ideias sobre redes aleatórias, capazes de funcionar com "ruído", com os conceitos correlatos do papel do acaso e da aprendizagem.

Já a partir do final da década de 50 , em oposição ao comportamentalismo que rejeitava o estudo dos estados mentais internos, começava a adquirir relevância o cognitivismo. Essa tendência advogava a complexificação do estudo do comportamento humano e o retorno de temas como a intencionalidade dos atos mentais e a consequente responsabilidade do indivíduo frente a eles. Turkle (1995) assinala que no final da década de 60, "a presença do computador legitimou o estudo da memória e de estados internos na psicologia.... os engenheiros estavam usando termos mentalistas que os psicólogos 'soft' queriam usar, mas tinham aprendido que não eram científicos" (p. 128). Turkle (1995) estava se referindo a termos como "objetivos"," pensamentos" e "intenções" que tinham sido banidos do léxico psicológico pelos comportamentalistas. 
A partir dos inúmeros desenvolvimentos tecnológicos mencionados anteriormente, o movimento cognitivista participou da articulação das novas áreas científicas que se propunham a criar artefatos que pudessem simular o comportamento mental racional.Temos, assim, psicologia, filosofia da mente, lógica, cibernética, teoria da informação, biologia, física, química, linguística, buscando a integração necessária para o desenvolvimento de uma "máquina inteligente", isto é, de computadores cada vez mais sofisticados que pudessem fazer uma simulação do comportamento humano.

Mais genericamente, a ciência cognitiva estuda a natureza da relação mente/cérebro. Porém, diferentemente da psicologia, ela começa a desenvolver a concepção de que o modelo mais viável para se estudar a mente/o cérebro seria o computador, na medida em que esse seria capaz de reproduzir algumas capacidades e funções da mente humana. Está, portanto, interessada em utilizar processos computacionais e informacionais para entender os processos cognitivos, ou melhor, em usar conceitos computacionais para explicar a mente/o cérebro. A fórmula "mente/cérebro" pertence às analogias feitas entre a mente e o computador. Assim, a mente seria análoga ao software, e o cérebro, ao hardware. E tal como o computador consiste em hardware e software, a pessoa consistiria em cérebro e mente (Dennett, 1985; Searle, 1998). Essa seria a Inteligência Artificial (IA) Forte, segundo a denominação crítica de Searle (1998), fadada ao fracasso na medida em que recusa a materialidade corporal característica de todo ser vivo.

Se essa tinha sido a orientação central da Ciência Cognitiva dos anos 50 aos anos 70, a década de 80 conheceu uma nova tendência, o conexionismo, que retomava alguns conceitos da cibernética. Ancorado no sucesso de pesquisas no campo já então denominado de neurociência, o conexionismo tinha como uma de suas prioridades simular o caráter autoorganizador do cérebro humano. Os pesquisadores utilizaram simulações em computador de redes neurais ou de processos biológicos. Criaram simulações com 'neurônios' artificiais ou formais, 'sinapses', etc., como se fazem simulações meteorológicas ou de construções de prédios, utilizandose várias ferramentas matemáticas como as lógicas paraconsistentes ou as lógicas nebulosas. Nessa nova tendência, chamada de Inteligência Artificial emergentista, também encontrava lugar o conhecimento mais recente da neurociência sobre a arquitetura neuronal: a existência de redes neurais, o processamento da informação em paralelo, a influência dos neurotransmissores sobre o funcionamento cerebral.

Turkle (1995) afirma que uma diferente analogia com o cérebro foi fundamental para o conexionismo. Assim, a forma mais adequada de construir uma "máquina inteligente" seria simular o modo de funcionamento cerebral.Ele faria as conexões "bottom-up" (ascendentes), e não"top-down" (descendentes): o sistema aprenderia através de uma quantidade imensa de diferentes conexões e, nesse sentido, seria imprevisível e não-determi- 
nista. O modelo conexionista não é construído sobre regras, por exemplo, para reconhecer rostos humanos, mas "treina" uma rede de neurônios artificiais que é "recompensada" ao reconhecer corretamente um rosto. $\mathrm{O}$ sistema no qual esse procedimento se baseia é aquele onde não existe um único programa que rege todo o sistema. Pelo contrário, trata-se de um conjunto de "pequenos programas chamados 'agentes', cada um com um conjunto pequeno e bem delimitado de regras a seguir, e um pequeno conjunto de dados no qual baseia suas decisões" (Turkle, 1995, p. 130).

Em resumo, o conexionismo toma como modelo redes de neurônios formais e procura construir um sistema cognitivo partindo de elementos simples que possam ligar-se entre si através de conexões. Sua concepção básica é que o pensamento humano não procede por passos lógicos, e sim através da interação entre microunidades de informação, da qual emerge a solução de um problema. Numa rede conexionista, não se procede à resolução de problemas por cálculos em sequências de passos lógicos. Diversamente, opera-se em paralelo, sem controle central, por um efeito das interações locais. Para o conexionista, a cognição emerge de estados globais numa rede de componentes simples, com regras locais que geram as operações individuais e regras de mudança que geram os vínculos entre os elementos.

\section{Uma nova idéia de cognição, uma nova idéia de cérebro}

Dupuy (1996) afirma que a biologia molecular pôde se constituir a partir do conceito de programa genético, junção de metáforas cibernéticas e informáticas. É importante enfatizar que as atualmente designadas "neurociências" surgem a partir da década de 1970, a partir de desdobramentos da biologia molecular que se referem especificamente à estrutura do sistema nervoso, incluindo o funcionamento neuronal, sub-neuronal, as redes de relações entre neurônios, as relações entre as estruturas cerebrais e as relações dessas com o organismo como um todo. Essa observação de Dupuy vai ao encontro da proposta de Searle de uma Inteligência Artificial Fraca, ou seja, que não nega a dimensão biológica e corporal, isto é, as peculiaridades do fenômeno da vida.

Assim, na gradual redefinição dos fenômenos da vida implementada pelos biólogos, os organismos passaram a ser considerados como sistemas auto-organizadores. Isto é, são considerados por sua capacidade de suportar situações de extrema turbulência/desorganização e, a partir daí, encontrarem novas soluções, reorganizando-se; basicamente, essa é a ideia da ordem a partir do ruído, sendo "ruído" um termo oriundo da teoria da informação relativo ao "padrão de desorganização" (Atlan, 1986/1992). Em outras palavras, um organismo vivo foi definido basicamente como aquele que tem a capacidade de se organizar/reorganizar por si próprio nas situ- 
ações de máxima instabilidade/ruído. Está constantemente adaptando-se e modificando sua representação interna face a um ambiente não-estacionário. Com isso, o processo de regulação dos organismos vivos passou a ser entendido como muito mais complexo e dinâmico do que se imaginava.

Aqui, emergia uma nova questão, qual seja, a da redefinição da cognição. Não era mais o caso de considerar a cognição como comportamento regulado por representações que incluem imagens mentais e representações viabilizadas pela linguagem. Era preciso levar em conta a concepção de que o manejo das informações que permitem ao ser vivo sobreviver (mesmo uma célula) também permite que esse reconheça substâncias, modificações do meio exterior e do meio interior de tal maneira que sua organização interna e seu comportamento externo estejam assegurados. Tais são operações que apresentam um caráter cognitivo - em nova definição - na manutenção da auto-organização do ser vivo.

O léxico do discurso biológico passou a conter palavras como informação, instrução, programa, código, tradução do texto genético, mensageiro molecular do DNA. Isto é, o ser vivo passou a ser concebido como um sistema de informação. Mas não à moda cognitivista. Definir o ser vivo como um sistema significa pensá-lo a partir de relações, isto é, em termos de sua organização, na qual as relações que a configuram são relações entre processos de produção de seus componentes. É evidente que nessas "zonas de comércio" (Thaggard, 1993) entre várias áreas de conhecimento existem dificuldades de comunicação e de cooperação, tentativas bem ou mal sucedidas de superar diferenças, como comerciantes de diferentes grupos culturais sempre fazem. E existem também lugares propícios, instituições que dão espaço e oportunidades para que se desenvolvam contatos interdisciplinares e colaborações. Para se constituírem, é preciso pessoas que estejam propensas a aprender outras línguas, outros vocabulários, outras culturas. E a discutir as dificuldades e os mal-entendidos.

Os programas de criação de máquinas inteligentes a partir da IA concebida em termos lógico-formais não atenderam às expectativas nela depositadas (devido ao fracasso em produzir máquinas inteligentes a despeito das previsões otimistas), às críticas aos modelos simbolistasrepresentacionistas de linguagem utilizados e às novas descobertas da arquitetura neuronal. $\mathrm{O}$ mais relevante para nós consiste no fato de que, já no início dos anos 90, os pesquisadores em IA emergentista/conexionista estavam utilizando maciçamente metáforas biológicas e sociais para falar de computadores e de humanos. Não mais simplesmente cumprirse-iam instruções. Tratava-se então de relacionar agentes, construir programas orientados para objetos, isto é, criar objetos internos ao computador programados para agir como pessoas ${ }^{4}$. Além disso, a utilização da palavra

4 Um exemplo conhecido desses novos artefatos são os jogos em computador que simulam cidades, sociedades, etc. Atualmente temos jogos de complexidade espantosa, que simulam as interações entre pessoas; por exemplo, os jogos de guerra. 
"agente" permitiu estabelecer rapidamente analogias com a psicologia e a sociologia, por exemplo.

A transição do processamento da informação para a IA emergentista trouxe também importantes mudanças nas ideias sobre determinação. De estreitas, elas tornaram-se amplas e abertas, abrindo espaço para o desenvolvimento da ideia de que não se pode, a partir dos elementos constituintes de um sistema, prever ou determinar as propriedades que tal sistema apresentará a partir de sua relação com o meio (Johnson, 2002). Contudo, o uso cada vez mais frequente de simulações em computador não é ponto pacífico entre os biólogos e tem sido questionado, sobretudo, pelos limites que tal modelo apresenta. Afirma-se não ser possível definir exatamente, ou prever, os fenômenos da natureza; o que existe é o que chamam de deriva (ver, por exemplo, Damásio, 1998, 2002; Gould, 1992; Varela, 1991).É por isso que alguns neurocientistas (Damásio, 1998, 2000; Edelman, 1992, 1999) têm rejeitado enfaticamente a ideia de que os processos biológicos, mesmo os aparentemente mais simples, possam ser explicados a partir da linguagem computacional. Isso porque os processos biológicos são demasiado complexos: as relações entre o ser vivo e o meio exterior são sujeitas a graus variáveis de determinação, com amplo espaço para o aleatório e o caótico. Quanto ao computador, seu uso só pode se dar, dentro de limites, para se fazer simulações de processos que possam ser definidos de maneira mais precisa.

Mas as divergências no campo são grandes. Por um lado, consideramse os processos neuronais como produtores da consciência, ela mesma entendida como um padrão do funcionamento do cérebro como sistema. Por outro lado, não é mais possível sustentar a afirmação de que o cérebro é uma máquina computacional, pois a computação é um artifício matemático que só se revela adequado e pertinente para seu estudo em determinados contextos. Além disso, as atuais concepções em neurociência não permitem que se pense a existência de uma mente sem um cérebro, como o software pode ser pensado na ausência do hardware. A mente está ancorada na coexistência de processos que ocorrem em um cérebro que, por sua vez, é incorporado, isto é, faz parte de um corpo em relação constante com um contexto singular.

É importante ressaltar que o paradigma computacional foi substituído por alguns teóricos pelo uso do paradigma informacional, no sentido mais lato das relações entre células como troca e reforço de informações, portanto, troca de sentidos. Não mais comparado a uma máquina - no caso, o computador - , o organismo é agora entendido como um sistema que se mantém funcionante pela troca contínua de informação com o meio e com outros organismos. Autores como Gazzaniga $(1985,1992)$ e Pinker (1997), partidários da neurociência cognitiva, defendem de maneira semelhante sua posição. Pinker (1997) coloca-se como partidário da teoria que afirma ser a mente o que o cérebro faz; e o que ele faz, e que nos per- 
mite ver, pensar, etc., é o processamento de informação, ou computação. Ambos os autores afirmam ainda que essa teoria permite incluir crenças e desejos sob a forma de informações fornecidas ao organismo, nas explicações do comportamento, "[permitindo] que o significado seja causa e seja causado" (Pinker, 1997. p.36). Além disso, em sua proposta de uma neurociência cognitiva, consideram de crucial importância os aspectos genéticos na estruturação de todo organismo, inclusive o humano.

Resumindo, existe uma relação consistente entre a construção de computadores cada vez mais sofisticados, que utilizam uma concepção conexionista de computação, o movimento cognitivista e o desenvolvimento de um campo científico específico, a neurociência. Como vimos, a partir da Segunda Guerra Mundial, ocorreu uma série de desenvolvimentos tecnológicos e conceituais que buscam estudar o humano como máquina e criar máquinas a partir dele. Essa proposta não é nova, proveniente que é do ideário racionalista ocidental, do projeto seiscentista de um tipo de conhecimento - a ciência - que considera a explicação da natureza possível a partir da descoberta das leis gerais que a regem. Por sua vez, estancar nosso raciocínio nesse ponto seria impedir-nos de ver a complexidade do campo científico que está se delineando.

\section{Conclusão: biologia e psicologia}

As possibilidades de uma aproximação entre o campo "psi" e a biologia contemporânea tem como pano de fundo o contexto histórico e epistemológico aqui esboçado. As contribuições da biologia abrangem um amplo leque de contribuições de teorias oriundas de várias ciências. Assim, toda análise que se possa desenvolver quanto às contribuições da biologia e as áreas conexas para as ciências humanas deverá se iniciar pelo reconhecimento da complexidade teórica envolvida. Certamente, não se trata de advogarmos em favor do determinismo biológico. Esse afirma, em síntese, que os comportamentos humanos específicos teriam uma base genética determinada. A partir dessa afirmação de princípio, diferenças internas numa sociedade que se pretende "igualitária" foram e são justificadas recorrendo-se a essas explicações que, na verdade, não pertencem propriamente à biologia, consistindo seus usos em apropriações pelos dispositivos ideológicos e políticos, segundo os quais as diferenças entre as pessoas seriam inevitáveis, já que naturais - , o que justificaria a desigualdade social, ao invés de se problematizar seu caráter sócio-histórico. Discutindo em profundidade essas questões, Gould (1992) propõe o conceito de "potencialidade biológica" a partir do qual pensa o biológico como amplas gamas de variações que não se referem a comportamentos específicos, mas, sim, a espectros de comportamentos possíveis. Com isso, o autor abre espaço para a flexibilidade humana no contexto biológico. 
Muito menos estamos de acordo com as propostas da sociobiologia (Wilson, 1981), que pretende incorporar as ciências sociais à biologia a partir do estudo sistemático das bases biológicas dos comportamentos sociais, isto é, dando explicações biológicas para todos os fenômenos culturais, da religião ao genocídio. Diversamente, consideramos que as teorias científicas são subdeterminadas e contingentes e que as escolhemos por motivos pragmáticos (Coutinho, 1996). Ora, o reducionismo metodológico é uma condição incontornável da prática científica. Do ponto de vista pragmático e levando em conta as ressalvas acima, podemos considerar as teorias biológicas como uma forma interessante de contribuição para o entendimento da vida.

Por exemplo, no que se refere ao conceito de evolução, Edelman (1992) defende o argumento de que as explicações sobre o comportamento em termos de psicologia social teriam muito a ganhar se levassem em consideração as contribuições da biologia. Ora, explica o autor, os fenômenos descritos pela psicologia dependem da espécie em que são observados e as propriedades das espécies dependem, por sua vez, da seleção natural - o que aproxima inexoravelmente a biologia da psicologia ao demonstrar a importância do caráter evolutivo do comportamento das espécies. Da mesma maneira, ao investigarmos o psiquismo humano, também devemos levar em conta, quer nosso parentesco com outras espécies, quer nossas diferenças. Dito de outro modo, Edelman (1992) acredita que

a base fundamental para todo o comportamento e para a emergência do espírito é a morfologia animal e da espécie (anatomia) e a maneira como ela funciona. A seleção natural age sobre os indivíduos enquanto eles competem entre si e com as outras espécies. Ao estudar os registros paleontológicos, descobre-se que aquilo que chamamos mente só emergiu em determinados períodos da evolução (aliás bastante tardia. (p.67)

A proposta de Edelman é a produção de um programa de pesquisa que conecte psicologia e biologia para dar conta do que ele chama de incarnação, ou seja, da emergência e do funcionamento do psiquismo.

Bastante diferente das proposições de Edelman, outro bom exemplo de como a biologia contemporânea e a psicologia podem se aproximar se encontra no livro Da biologia à psicologia do biólogo Humberto Maturana (1995). Nele, o autor afirma que, embora possua um domínio próprio, a psicologia penetra na biologia, na medida em que estuda fenômenos que ocorrem no viver dos seres vivos. Tal domínio próprio é o do estudo das condutas entendidas como a dinâmica das relações e interações dos animais, especificamente o homem, entre si e com o seu meio. Porém, quando a psicologia se debruça sobre como se estabelecem os fenômenos que observa, algumas perguntas que formula têm relação com a gênese das condutas e não somente como sua dinâmica interna. Nesse ponto, a psicologia 
penetra na biologia e exige uma interação de perguntas que conjugam os pontos de vista biológico e psicológico ao mesmo tempo. Segundo a definição de Maturana (1995),

o âmbito próprio da psicologia é o do estudo da dinâmica de relações e interações dos organismos como totalidades e o âmbito próprio da biologia é o estudo da geração das circunstâncias e condições sob as quais os organismos realizam suas condutas. (p. 180)

Nesse sentido, o psiquismo ou a mente e seus mecanismos devem ser pensados como um aspecto dessa dinâmica da relação entre organismos, ou melhor, como uma propriedade do sistema vivo gerada em seu operar em um determinado contexto.

Neste operar, o organismo é modificado pelo meio, pois se alimenta de informação. Tal afirmação pode ser entendida de duas maneiras. A primeira é considerar metaforicamente a noção de informação, utilizando o termo por referência à congruência operacional estabelecida nas interações de um organismo com o seu meio, como se tal congruência derivasse da captação pelo organismo, das características do meio através da captação de informações (Maturana, 1995). Nesse caso, a noção de informação tem somente um caráter evocativo, e não um valor explicativo, pois deixa em aberto as questões sobre os mecanismos que dão origem a tal congruência operacional entre organismo e meio. A segunda maneira de entender a afirmação inicial decorre da consideração da noção de informação no lugar do próprio mecanismo gerativo da congruência operacional organismo-meio, o que estaria em contradição com a visão dos seres vivos como determinados estruturalmente. Aqui, o pressuposto é o de que o meio especifica o que acontece no organismo, o que negaria o determinismo estrutural dos seres vivos (Maturana, 1995). Em biologia, a noção de informação só é útil se tiver um valor metafórico, e não explicativo.

Assim, também a pergunta sobre como as crenças afetam os indivíduos ou como as informações que alguém diz obter do mundo têm consequências no seu modo de operar devem, para Maturana (1995), ser respondidas sem violar a condição constitutiva dos seres vivos como sistemas estruturalmente determinados. Mas, para respondê-las, devem-se aceitar certas distinções fenomenológicas como, por exemplo, que a fisiologia do organismo ocorra em um domínio diferente daquele no qual ocorrem as condutas. Tais domínios sendo disjuntos, a relação entre eles seria somente gerativa ortogonal na dinâmica de mudança estrutural. Dito de outro modo, o comportamento de cada organismo seria determinado a cada momento pelo acoplamento estrutural entre o sistema-organismo e o meio com o qual interage. Assim, o psíquico estaria na dinâmica relacional do ser vivo, determinada pela história de suas interações com o meio que, 
por sua vez, transformaram estruturalmente sua dinâmica interna ao longo do tempo (Maturana, 1995).

Esse breve exemplo ilustra o interesse das possíveis aproximações entre psicologia e biologia contemporânea a partir das reflexões e dos desdobramentos conceituais aqui apresentados. Poderíamos também incluir como parte intrínseca dessa discussão conceitos relacionados à subjetividade, à cultura, à linguagem, à emoção, anteriormente considerados posse exclusiva das ciências humanas e sociais e, agora, inseridos na agenda das ciências da vida. Evidentemente, não se trata de remeter a psicologia à biologia, acreditando estar aí a sua verdade fundamental. Pelo contrário, o que o exemplo de Maturana nos mostra é que é possível encontrar não apenas interesses comuns, mas, principalmente, pontos de interseção nos quais o pensamento torna-se particularmente fértil, podendo enveredar por novos caminhos e enriquecer ambos os campos de saber.

\title{
Psychology and Biology: some Intersections
}

\begin{abstract}
Aiming at analyzing the possibilities of approximation between the fields of biology and psychology, the article selects key concepts relevant to the understanding of the importance of contemporary biology. Firstly it presents some often neglected theoretical, methodological and epistemological questions involved in the approximation between psychology and biology. Afterwards, it describes a brief historical account of the developments of biology and some of their appropriations by other theoretical fields in the course of the Twentieth Century. After a brief presentation of the theoretical approximations already done between the fields, it suggests that this movement constitutes a first step towards an informed and interested interlocution between these two fields.
\end{abstract}

Keywords: Biology. Psychology. Interdisciplinarity. Connectionism

\section{Psychologie et Biologie: quelques intersections}

Résumé: Certains concepts importants pour la compréhension de l'importance de la biologie contemporaine pour la psychologie ont été sélectionnés, afin d'examiner les possibilités de rapprochement entre les deux champs. Pour cela, d'abord, certaines questions théoriques, méthodologiques et épistémologiques impliqués dans le rapprochement entre la psychologie et la biologie, qui sont souvent négligés, sont presentés. Ensuite, un bref historique de l'évolution de la biologie et de 
certains de leurs crédits à d'autres champs théoriques au cours du XXe siècle ont été faites. Après une brève présentation des approches théoriques que ont eu lieu entre les deux domaines de connaissance, il est suggéré que ce serait un premier pas en cause et à un dialogue éclairé entre les deux champs.

Mots-clés: Biologie. Psychologie. Interdisciplinarité. Connexionisme.

\section{La Psicología y la Biología: algunas intersecciones}

Resumen: Son seleccionados algunos conceptos relevantes a la comprensión de la importancia de la biología contemporánea a la psicología a fin de examinar las posibilidades de acercamiento entre los dos campos. Para eso, primero hay que presentarse algunas cuestiones teóricas, metodológicas y epistemológicas que participan en el acercamiento entre la psicología y la biología, que a menudo son descuidadas. Después, preséntase una breve historia de la evolución de la biología y algunos de sus créditos de otros campos teóricos durante el siglo XX. Después de una breve presentación de los enfoques teóricos que se han llevado a cabo entre los dos campos del conocimiento en cuestión, se sugiere que ese sería un primer paso para un diálogo informado y interesado entre los dos campos.

Palabras clave: Biología. Psicología. Interdisciplinaridad. Conexionismo.

\section{Referências}

Atlan, H. (1992). Entre o cristal e a fumaça: ensaio sobre a organização do ser vivo. Rio de Janeiro: Jorge Zahar. (Trabalho original publicado em 1986)

Blackburn, S. (Ed.). (1988). Oxford companion to the mind. London: Oxford University Press.

Buchwald, J. Z. (2001). Incommensurability and the discontinuity of evidence. Perspectives on Science, 9(4), 463-498.

Coutinho, A. M. (1996). Cientificidade e relevância social - I: controvérsias sobre a cientificidade da psicologia e das ciências sociais. Psicologia: Teoria e Pesquisa, 12(1), 23-37.

Damasio, A. (1998). O erro de Descartes. Lisboa: Europa-América.

Damasio, A. (2002). O mistério da consciência. São Paulo: Companhia das Letras.

Dennett, D. (1985). Brainstorms: Philosophical essays on mind and psychology. Cambridge: The MIT Press. 
Dupuy, J-P. (1996). Nas origens das ciências cognitivas.São Paulo: Ed. UNESP.

Edelman, G. (1992). Bright air, brilliant fire. New York: Basic Books.

Edelman, G. (1999). A universe of consciousness, when matter becomes imagination. New York: Basic Books.

Feyerabend, P. K. (1985). Realism, rationalism and scientific method (Vol. 1). Cambridge: Cambridge University Press. (Trabalho original publicado em 1981)

Gazzaniga, M. S. (1985). El cerebro social. Madrid: Alianza.

Gazzaniga, M. S. (1992). Nature's mind. New York: Basic Books.

Gould, S. J. (1992). Darwin e os grandes enigmas da vida. São Paulo: Martins Fontes.

Jacob, F. (1983/1970). La logique du vivant. Paris: Gallimard.

Johnson, S. (2002). Emergence - the connected lives of ants, brains, cities and softwares. New York: Touchstone.

Kuhn, T. (2003). A estrutura das revoluções científicas. São Paulo: Perspectiva. (Trabalho original publicado em 1962)

Kuhn, T. (1977). A tensão essencial. Lisboa: Edições 70.

Laborit, H. (1988). Deus não joga dados. São Paulo: Trajetória Cultural.

Laudan, L. (1997). Progress and its problems: Towards a theory of science growth. Berkeley: University of California Press.

Latour, B. (1988/2000). Ciência em ação: como seguir cientistas e engenheiros sociedade afora. São Paulo, Ed. UNESP.

Lévi-Strauss, C. (1962). La pensée sauvage. Paris: Plon.

Maturana, H. (1995). Da biologia à psicologia. Porto Alegre: Artes Médicas.

Maturana, H., \& Varela, F. (1984). El árbol del conocimiento. Santiago: Universitária.

Mello Filho, J. (1994). Concepção psicossomática: visão atual (7a ed.). Rio de Janeiro: Tempo Brasileiro.

Monod, J. (1970). Le hasard et la necessité: essai sur la philosophie naturelle de la biologie moderne. Paris: Seuil.

Pinker, S. (1997). How the mind works. New York: Norton.

Prigogine, I., \& Stengers, I. (1984). A nova aliança: a metamorfose da ciência. Brasília: Ed. Universidade de Brasília.

Searle, J. (1998). O mistério da consciência. Petrópolis, RJ: Paz e Terra.

Schultz, D., \& Schultz, S. (2005). História da psicologia moderna. São Paulo: Pioneira.

Thaggard, P. (1993). Conceptual revolutions. Princeton: Princeton University Press.

Turkle, S. (1995). Life on the screen: identity in the age of the Internet. New York: Simon \& Schuster.

Varela, F. J. (1991). Connaître. Paris: Seuil. 
Varela, F., Thompson, E., \& Rosch, E. (1991). The embodied mind: cognitive science and human experience. Cambridge: The MIT Press.

Von Bertalanffy, L. (1968). General systems theory: A presentation. New York: George Braziller. (Trabalho original publicado em 1956)

Wilson, E. O. (1981). Da natureza humana. São Paulo: Edusp.

Flávia Sollero-de-Campos, Psicóloga clínica, Professora Assistente do Departamento de Psicologia/ PUC-Rio. Endereço eletrônico: fsollero@puc-rio.br

Monah Winograd, Psicanalista, Professora Assistente do Departamento de Psicologia/ PUCRio, Professora do Programa de Pós-graduação em Psicologia Clínica /PUC-Rio. Endereço para correspondência: Departamento de Psicologia/ PUC-Rio, Av. Marquês de São Vicente, 225/ Prédio Leme, sala 201, Gávea - Rio de Janeiro/RJ, CEP 22453-900. Endereço eletrônico: winograd@uol.com.br

Recebido em: $27 / 04 / 2008$

Aceito em: 8/12/2008 